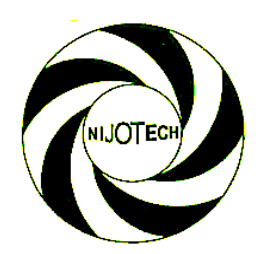

Nigerian Journal of Technology (NIJOTECH)

Vol. 37, No. 2, April 2018, pp. 537 - 542

Copyright@ Faculty of Engineering, University of Nigeria, Nsukka,

Print ISSN: 0331-8443, Electronic ISSN: 2467-8821

www.nijotech.com

http://dx.doi.org/10.4314/njt.v37i2.33

\title{
DESIGN, FABRICATION AND PERFORMANCE EVALUATION OF A PORTABLE HAND-HELD REFRACTOMETER
}

\author{
K. C. Ugwu ${ }^{1}{ }^{*}$, C. C. Mbajiorgu ${ }^{2}$, W. I. Okonkwo ${ }^{2}$ and A. O. Ani ${ }^{3}$

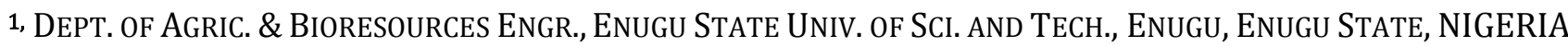 \\ 2,3,4, DEPT. OF AGRIC. AND BIORESOURCES ENGINEERING, UNIVERSITY of NigERIA, NSUKKA ENUGU STATE, NIGERIA \\ E-mail addresses:1chikwadok@yahoo.com, 2 constantine.mbajiorgu@unn.edu.ng, \\ 3wilfred.okonkwo@unn.edu.ng, ${ }^{4}$ ozoemena.ani@unn.edu.ng
}

\begin{abstract}
Refractometer is a simple optical instrument that measures the amount of light refracted in a liquid. It measures on a "Brix" scale and the Brix level determines the flavor and quality of fruits and vegetables. The fabricated refractometer has built-in temperature compensations for Brix measurements and it is only valid for fruit juices solutions The refractometer is equipped with a thermometer and there is a means of circulating water through the refractometer to maintain a given temperature The designed refractometer consists of a light source, filtered to a single wavelength, which is directed towards the prism-sample interface by a converging lens. This creates a range of incidence angles, some of which will be completely reflected. A Charge-coupled Device (CCD) sensor precisely measures the intensity of the reflected light and determines the exact angle at which light begins to be completely reflected. The fabricated refractomter consists of six main parts which include focus adjustment, calibration screw, daylight plate, eye piece, rubber grip and main prism assembly. Actual tests were conducted using samples of orange, pineapple and cashew juices at certain levels of $\mathrm{pH}$ values. The average percentage Brix values of orange, cashew and pineapple juices are 7.88\%, 10.84\% and 6.91\% respectively. It was observed that cashew juice has highest percentage Brix followed by orange and pineapple juices. This implies that cashew juice can deteriorate faster than the other two juices. The analysis of variance (ANOVA) for the effect of temperature and $\mathrm{pH}$ used for the experiment show that $F$-calculated (4.248) is greater than F-table (3.35) at 5\% probability level; therefore, the $\mathrm{pH}$ of fruit juice has an effect on its brix value. It appears that the rate of $\mathrm{pH}$ or temperature sensitivity of the fabricated refractometer used could not be the actual or maximum rate for the experiment
\end{abstract}

Keywords: Design, Fabrication, Portable, Refractometer, pH, Temperature

\section{INTRODUCTION}

Refractive Index is the speed of light in vacuum relative to the speed of light in the considered medium. The refractive index is commonly determined as part of the characterization of liquid samples, in much the same way that melting points are routinely obtained to characterize solid compounds. Whenever light changes speed as it crosses a boundary from one medium into another its direction of travel also changes, that is, it is refracted. The refractive index depends not only on the wavelength used to measure it, but also on the temperature of the solution being measured [1].

The Brix degree represents the concentration in weight percent of a mixture of pure sucrose and water. It is used as the weight percentage concentration of sucrose in general. This concentration is calculated from the measured refractive index using the stored concentration table (16th conference of the International Commission of Uniform Methods for Sugar Analysis, [2]. The result is given at the standard reference temperature of $20^{\circ} \mathrm{C}$ using the temperature dependence for these solutions from the same source. So the refractive index and the prism surface temperature are measured and the Brix is calculated from the tables. When substances other than sucrose are present, Brix is calculated from the total refractive index. In such a case the result in Brix will not indicate the real sucrose concentration [3].

A refractometer is a laboratory or field device for the measurement of an index of refraction (refractometry). Refractometer is a simple optical instrument that measures the amount of light refracted in a liquid. 
Refractometers measure on a "Brix" scale and measuring the Brix level of fruits and vegetables is very important because it is a great indicator of flavor and quality [4].

The higher the brix level of your fruits juices, the higher the dissolved solids in the fruits juices such as sucrose, fructose, vitamins, minerals, amino acids, proteins, hormones and all other nutrients that the plant puts into the foods. It is estimated that in a healthy fruit or vegetable, approximately $80 \%$ of the brix is represented by the natural sugars which give the food its great flavor and goodness. It is believed by many people to be the best indicator of quality available in one quick and simple test [5].

Different models of hand-held refractometers have different internal scales on which to read fluid concentrations. Some instruments have specialized scales that indicate the exact mixture of the sample being tested, while others have an arbitrary unit of measure that works like shorthand for refractive index measurements [6].

Hand held refractometers are one of the most popular analytical devices. They are used in many places - like in wine growing and wine making, both by professionals and amateurs, in beer brewing, in garages to check battery electrolyte and cooling liquid quality, and so on. They are very simple to use and give almost instant result, without tedious and costly laboratory procedures to follow [7].

The refractometer is a relatively simple device for measuring the angle of refraction at the liquid-solid phase interface. The angle of refraction depends on the composition of the solution, which allows the use of refractometers for quick evaluation of concentration of dissolved substances. They can also be used, although to a lesser extent, to study the structure of chemical compounds [8].

To take care of temperature differences, simple handheld refractometers have to be either calibrated before taking measurements (using calibration screw and distilled water), or the result have to be converted using a temperature corrections table (which requires separate temperature measurement). However, many refractometers have in-built temperature compensation - either scale or additional optical wedge are mounted on the bimetallic strip [9].

The soluble solids and ascorbic acid are primarily sugars; sucrose, fructose, and glucose. As the flesh of fruit forms, it deposits nutrients such as starch, as the fruit ripens, it transforms to sugar. The percentage sugar, measured in degrees Brix indicates the sweetness of the fruit by measuring the number of soluble solids in the juice source. Citric acid and minerals in the juice also contribute to the soluble solids. The ratio of the Brix to total acid reading must be above a certain tolerance level. Oranges need the sugar level for sweetness and the acid for a tart taste and preservation of the fruit [10].

The brix value or refractive index of fruits juice is important for determination of storage duration of the juice. The higher the brix value of fruit juice, the higher the dissolved solid contents in the juice. The level of dissolved solids in fruit juice determines the storage duration of the particular juice. The objectives of this research is to design and fabricate a portable hand held refractometer, with available materials that will be used in determining refractive index of a fruit juice from orange, cashew and pineapple samples and its performance evaluated

\section{MATERIALS AND METHOD}

The materials with significantly different physical properties that, when combined, produced a material with characteristics different from the individual components are used for the construction. The individual components remain separate and distinct within the finished structure. The new material may be preferred for many reasons: common examples include materials which are stronger, lighter, or less expensive. The materials used in the construction of the refractometer include Prisms, Cylinder, Biometric strips, Scale, Lens, Illuminating flap, Reflector, Lamp, Mirror, Rubber Grip, Calibration Screw, Sensor, etc.

\subsection{Location of the research}

The Hand held Refractometer was designed and fabricated using Mechanical and Agricultural and Bioresource Engineering workshops of Enugu State University of Science and Technology, Enugu, Nigeria.

\subsection{Design considerations}

Distilled water will be used to test the sample to learn how to use the refractometer and its index of refraction is 1.3329 at $20^{\circ} \mathrm{C}$ of temperature. It is also designed based on the reflection of light from the boundary between the prism and the sample. The compensating prisms are designed so that they can be adjusted to correct (i.e., compensate for) the dispersion of the sample in such a way that they reproduce the refractive index that would be obtained with monochromatic light of $589 \mathrm{~nm}$, the sodium D line.

\subsection{Design calculations and Selections 2.3.1 Triangular prism}

A right triangular prism has a triangular base in which the joining edges and faces are perpendicular to the 
base edges. In a right triangular prism, all the lateral faces are rectangles and are perpendicular to the bases.

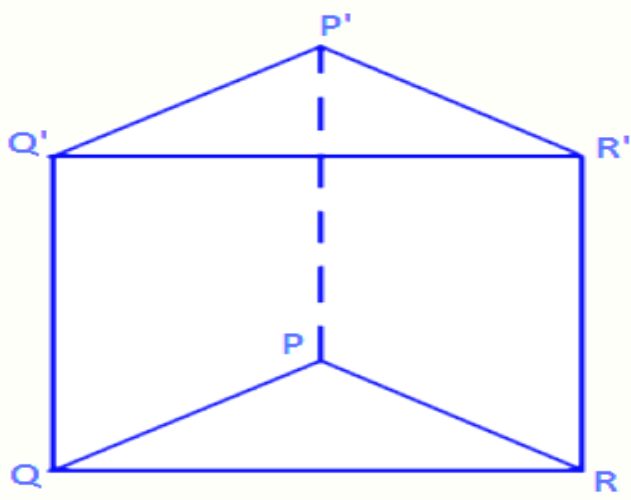

Fig 1: Triangular prism

Total surface area of the triangular prism $=$ Lateral surface area of the prism + Area of two bases $=((\mathrm{a}+$ $b+c) h+1 / 2 b h$ ) square units

\subsubsection{Surface area of cylinder}

An open cylinder does not include either top or bottom elements, and therefore has surface area (lateral area).

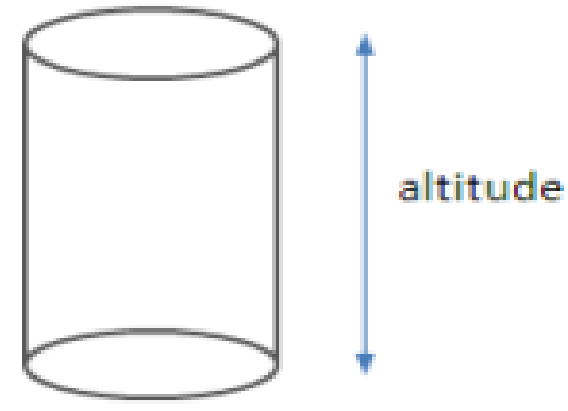

Fig 2: An Open cylinder

The total surface area of a closed cylinder is made up the sum of all three components: top, bottom and side, which is

$$
\begin{gathered}
A^{0}=2 \pi r^{20}+2 \pi r h^{0}=2 \pi r\left(r^{0}+{ }^{0} h\right)=\pi d r\left(\mathrm{r}^{0}+{ }^{0} \mathrm{~h}\right) \\
=L+2 B
\end{gathered}
$$

Other parts were selected based on the functional use on the refractometer.

\subsection{Assembly/Description of the equipment}

The fabricated refractomter consists of six main parts which include focus adjustment which is used to adjust the reading at centre, calibration screw is used to set the reading at zero before any experiment, daylight plate is where the water or the juice material to be determined its brix values is placed, eye piece is the eye is located to take the reading, rubber grip joins focus adjustment, daylight plate and the calibration screw and main prism assembly. These parts are joined together using fasteners and electrodes.

\subsection{Performance evaluation of the refractometer}

The actual tests were conducted using samples of orange, pineapple and cashew juices at certain levels of $\mathrm{pH}$ values. The average percentage Brix values of orange, cashew and pineapple juices were determined and tabulated. The analysis of variance (ANOVA) for the effect of temperature and $\mathrm{pH}$ used for the experiment was determined at 5\% probability level.

\subsection{Selection of Optical Sensors}

A sensor is any device that takes a physical quantity, measures it, and converts it into information that can be read and understood by an observer. There are a wide variety of means by which a sensor collects and converts data, many of them not involving any electronics at all. All sensors share one general characteristic: they are transducers. A transducer is a device for transforming one type of energy into another. For example, even a simple mercury thermometer works by taking heat energy and changing it to the volumetric expansion or contraction of liquid for the purposes of measurement. Therefore, all sensors can be categorized according to the kind of energy they detect and convert. These categories are: acoustic, chemical, electromagnetic, ionizing radiation, mechanical, optical, and thermal. The sensor was selected based on the kind of work it is going to perform, which is optical.

\subsection{Principle of Operation of a Refractomenter}

The Figures 3 is labeled diagram of fabricated hand held refractometer and Figure 4 is exploded Isometric View of Fabricated Refractometer and The operation of the refractometer is based on the physical principle of light refraction (Snell's law). Light slows down as it passes into more optically dense media, and speeds up as it passes into less optically dense media. The change in speed is accompanied by a change in direction, and at a certain angle of incidence, the light does not refract in the second medium at all, but is entirely reflected. The angle at which this occurs is known as the critical angle, and it is this angle that the refractometer measures. A refractometer consists of a light source, filtered to a single wavelength, which is directed towards the prism-sample interface by a converging lens. This creates a range of incidence angles, some of which (those less than the critical angle) will be completely reflected. A Charge-coupled Device (CCD) sensor precisely measures the intensity of the reflected light and determines the exact angle ( $\left.\alpha_{\text {critical }}\right)$ at which light begins to be completely reflected. Since this angle is dependent on the ratio of the refractive index of the prism to that of the sample, the refractive index of the 
sample can be determined using the known refractive index of the prism.

\subsection{General Steps for Calibration}

1. Inspect the refractometer prism for scratches, chips, separations or other aberrations that will interfere with proper readings. If dusty rinse with water and wipe with a clean, soft, lint-free cloth.

2. Note the temperature at the time of readings. Most ATC refractometers operate properly in the 20 $30^{\circ} \mathrm{C}\left(68-86^{\circ} \mathrm{F}\right)$ range. A laboratory or office at room temperature is used if out- side temperatures exceed the manufacturer's recommended temperature range.

3. Place a few drops of pure water on the prism surface, close the cover. If bubbles form, gently pressing the cover that removes the bubbles and help disperse the water over the entire surface.

4. Hold the refractometer up to natural light or an incandescent bulb to obtain the reading. Looking into the eyepiece, a distinct separation between a blue and white section is seen, and it is called a "contrast" line. If the contrast line is not directly at zero, then adjust by turning the screw on the top of the refractometer until it reads zero. The plastic cap is replaced after adjusting the calibration screw to prevent water from entering the refractometer. Adjust the focus by turning the eyepiece until the scale is seen clearly. Once the refractometer is calibrated to zero with pure water, dry the surfaces with a clean cloth.

5. Place some of the solution from the 5-packet bottle on the prism and close the cover, making sure that the entire surface is filled and void of bubbles. Note the value and write it down. The value will remain on the LED display until the next sample is read.

\section{RESULTS AND DISCUSSION}

The results obtained for the determination of refractive index and percentage Brix of orange juice, cashew and pine apple juice are presented in Tables 1-4.

The Table 1 shows the results obtained during the test of orange juice with the fabricated refractometer, it also shows that, the lowest $\mathrm{pH}$ of 3.03 has the refractive index of 1.340 and the highest scale of $\mathrm{pH}$ of 3.85 has the refractive index of 1.348 . It means that the higher the $\mathrm{pH}$ of orange juice the higher the refractive index at $20^{\circ} \mathrm{C}$ of temperature. It was also shown that orange juice can be consumed at maximum percentage brix value of $11 \%$.

The results obtained during the test of cashew juice with the fabricated refractometer were presented in
Table 2. It also shows that the lowest $\mathrm{pH}$ of 3.20 has the refractive index of 1.340 and the highest $\mathrm{pH}$ of 4.0 has the refractive index of 1.357 . The results also showed that cashew juice has higher acid, total solid content and sugar than orange and pineapple juices. This means that it can deteriorate faster than orange and pineapple juices.

The results obtained during the test of pineapple juice with the fabricated refractometer are presented in Table 3. It shows that the lowest $\mathrm{pH}$ of 3.05 has refractive index of 1.337 and the highest $\mathrm{pH}$ scale of 3.86 has the refractive index of 1.354 . It was observed that pineapple and orange has almost the same $\mathrm{pH}$, Brix value and refractive index. Table 4 presents the results on analysis of variance (ANOVA) for the effect of temperature and $\mathrm{pH}$ used for the experiment. The results show that $\mathrm{F}$-calculated (4.248) is greater than $\mathrm{F}$ table (3.35) at 5\% probability level; therefore, the $\mathrm{pH}$ of fruit juice has an effect on its brix value. It appears that the rate of $\mathrm{pH}$ for the fruit juice used on the fabricated refractometer could not be the actual or maximum rate for the experiment.

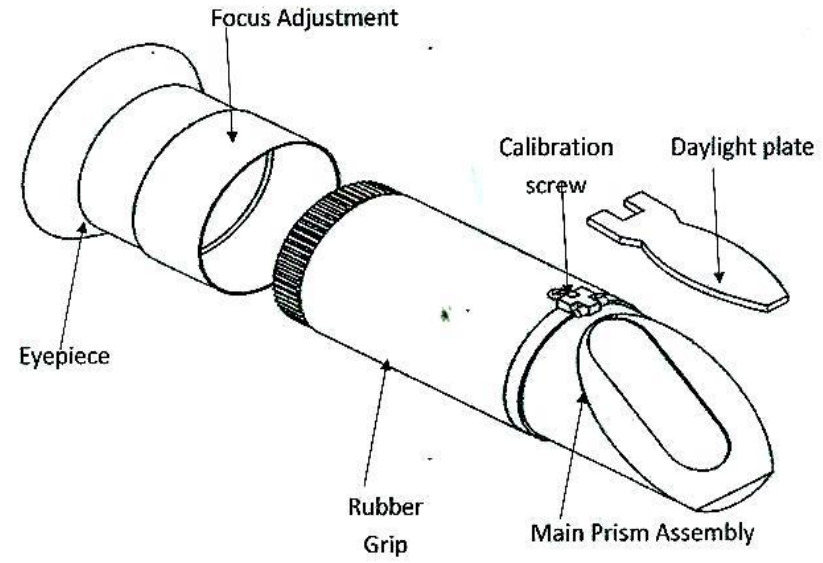

Figure 4: Exploded Isometric View of Fabricated Refractometer

Table 1: The $p H$, Percentage Brix and Refractive Index of Orange Juice.

\begin{tabular}{ccccc}
\hline S/N & $\begin{array}{c}\text { Orange } \\
\text { pH }\end{array}$ & $\begin{array}{c}\% \\
\text { Brix }\end{array}$ & $\begin{array}{c}\text { Temperature } \\
{ }^{\circ} \mathrm{C}\end{array}$ & $\begin{array}{c}\text { Refractive } \\
\text { Index }\end{array}$ \\
\hline 1 & 3.03 & 4.8 & 20 & 1.340 \\
2 & 3.14 & 5.5 & 20 & 1.341 \\
3 & 3.12 & 6.2 & 20 & 1.342 \\
4 & 3.15 & 7.5 & 20 & 1.344 \\
5 & 3.22 & 8.1 & 20 & 1.345 \\
6 & 3.34 & 8.8 & 20 & 1.346 \\
7 & 3.51 & 8.8 & 20 & 1.346 \\
8 & 3.54 & 9.5 & 20 & 1.347 \\
9 & 3.62 & 9.5 & 20 & 1.347 \\
10 & 3.85 & 10.1 & 20 & 1.348 \\
\hline
\end{tabular}


Table 2: The $\mathrm{pH}$, Percentage Brix and Refractive Index of Cashew Juice.

\begin{tabular}{ccccc}
\hline \multirow{2}{*}{$\mathrm{S} / \mathrm{N}$} & $\begin{array}{c}\text { Cashew } \\
\mathrm{pH}\end{array}$ & $\begin{array}{c}\% \\
\text { Brix }\end{array}$ & $\begin{array}{c}\text { Temperature } \\
{ }^{\circ} \mathrm{C}\end{array}$ & $\begin{array}{c}\text { Refractive } \\
\text { Index }\end{array}$ \\
\hline 1 & 3.20 & 4.8 & 20 & 1.340 \\
2 & 3.21 & 6.8 & 20 & 1.343 \\
3 & 3.22 & 7.5 & 20 & 1.344 \\
4 & 3.40 & 8.8 & 20 & 1.346 \\
5 & 3.50 & 11.4 & 20 & 1.350 \\
6 & 3.51 & 12.7 & 20 & 1.352 \\
7 & 3.60 & 12.7 & 20 & 1.352 \\
8 & 3.70 & 13.3 & 20 & 1.353 \\
9 & 3.90 & 14.6 & 20 & 1.355 \\
10 & 4.0 & 15.8 & 20 & 1.357 \\
\hline
\end{tabular}

Table 3: The $\mathrm{pH}$, percentage Brix and Refractive Index of Pineapple Juice.

\begin{tabular}{ccccc}
\hline S/N & $\begin{array}{c}\text { Pineapple } \\
\text { pH }\end{array}$ & $\begin{array}{c}\% \\
\text { Brix }\end{array}$ & $\begin{array}{c}\text { Temperature } \\
{ }^{\circ} \mathrm{C}\end{array}$ & $\begin{array}{c}\text { Refractive } \\
\text { Index }\end{array}$ \\
\hline 1 & 3.05 & 2.8 & 20 & 1.337 \\
2 & 3.15 & 3.5 & 20 & 1.338 \\
3 & 3.22 & 4.1 & 20 & 1.339 \\
4 & 3.31 & 4.1 & 20 & 1.339 \\
5 & 3.46 & 4.8 & 20 & 1.340 \\
6 & 3.57 & 6.8 & 20 & 1.343 \\
7 & 3.67 & 8.8 & 20 & 1.346 \\
8 & 3.71 & 10.1 & 20 & 1.348 \\
9 & 3.79 & 11.4 & 20 & 1.350 \\
10 & 3.86 & 12.7 & 20 & 1.354 \\
\hline
\end{tabular}

Table 4: Analysis of variance (ANOVA) of the Brix value of the three samples determined

\begin{tabular}{lcccc}
\hline Sources of variation & $\begin{array}{l}\text { Degree of } \\
\text { Freedom }\end{array}$ & $\begin{array}{l}\text { Sum of } \\
\text { square }\end{array}$ & $\begin{array}{c}\text { Mean } \\
\text { Square }\end{array}$ & F-calculated \\
\hline $\begin{array}{l}\text { Among Treatment } \\
\text { Within Treatment (Experimental }\end{array}$ & 2 & 83.821 & 41.911 & 4.248 \\
$\begin{array}{l}\text { Error) } \\
\text { Total }\end{array}$ & 27 & 266.389 & 9.866 & 3.350 \\
\hline
\end{tabular}

To take care of temperature differences, the fabricated hand-held refractometer has to be calibrated before taking measurements (using calibration screw and distilled water), thermometer that take care of temperature compensations is built inside the refractometer but the result of other refractometers have to be converted using a temperature corrections table (which requires separate temperature measurement).

An Abbé refractometer was used to determine the brix values of these fruit juice and the results obtained were $7.3 \%$ brix at $\mathrm{pH}$ of 3.15 of orange, $11.3 \%$ brix at $\mathrm{pH}$ of 3.50 of cashew and $4.05 \%$ brix at $\mathrm{pH}$ of 3.22 of pineapple as against the values obtained using fabricated refractometer which include $7.5 \%$ brix at $\mathrm{pH}$ of 3.15 of orange, $11.4 \%$ brix at $\mathrm{pH}$ of 3.50 of cashew and $4.10 \%$ brix at $\mathrm{pH}$ of 3.22 of pineapple at $20^{\circ} \mathrm{C}$ of temperatures. The results obtained using the fabricated refractometer were in line with the Abbe refractometer measurements of the percentage Brix but the little variation was due to the conversion done on the Abbe refractometer.

\section{CONCLUSION AND RECOMMENDATION}

It is clear that the temperature correction is concentration dependent and therefore it is necessary to measure such a complex solution always at the desired temperature. This Hand-held refractometer has in-built temperature compensations for Brix measurements. This temperature compensation is only valid for fruit juices solutions and will give incorrect temperature compensations for other samples, (eg vegetables, wine, soft drinks and in the starch and sugar manufacturing industry).

The results obtained using the fabricated refractometer were in line with the standard measurements of the percentage Brix and refractive index of orange, pineapple and cashew juices. The standard refractive index of all the samples (fruit juices) ranged from 1.337 to 1.357 and the three samples measured are in line with existing standard. These values could be useful for quality control assessment during preparation of juices in food industry.

The percentage Brix measured of cashew, orange and pineapple juices of fresh fruit at the same temperature shows that cashew has highest $\mathrm{pH}$ and refractive index than the other two juices investigated.

Hand-held refractometers are convenient because they do not require an energy source. However, they may not be accurate if used outside the specified temperature range. Using an analog refractometer, whenever possible, within a specific field or block should be read by one person at a time, since readings are somewhat subjective.

\section{REFERENCES}


[1] Anne M. L., Keirsse J., Nazabal V., Hyodo K., Inoue S., Boussard-Pledel C., Lhermite H., Charrier J., Yanakata K., Loreal O., Le Person J., Colas F., Compère C. and Bureau B, "Chalcogenide Glass Optical Waveguides for Infrared Biosensing", Sensors, vol. 9(9), 2009, pp 7398-7411.

[2] International Commission of Uniform Methods for Sugar Analysis (ICUMSA) Methods Book, The Determination of Refractometric Dry Substance (RDS \%) of Molasses Accepted and Very Pure Syrups (Liquid Sugars), Thick Juice and Run-off Syrups Official",", op. cit.; Specification and Standard SPS-3, 2009

[3] Rekha C., Poornima G., Manasa M., Abhipsa V., Pavithradevi J., Vijay kumar H. T. and Prashith kekuda T. R., "Ascorbic Acid, Total Phenol content and Antioxidant activity of Fresh Juices Four Ripe and unripe Citrus Fruits", Journal of Chemical Science Transactions, Vol. 1, Issue 2, 2012, pp 303 -310 .

[4] Tilton, L. W. and Taylor, J. K., "Refractive index and dispersion of distilled water for visible radiation at temperatures 0 to $60^{\circ} \mathrm{C}$." J. Res. Natl. Bur. Stand. 20, pp. 419 - 477, 2008.

[5] Williams L. D., Okandon M., and Blair S., "Design and characterization of a microheater array device fabricated with SwIFT-Lite TM", J.
Micro/Nanoli MEMS MOEMS Vol.7, 2008, pp 035 - 043.

[6] Bahsi Z.B., Büyükaksoy A., Ölmezcan S.M., Imek F., Aslan M.H., Oral A.Y., "A Novel Label-Free Optical Biosensor Using Synthetic Oligonucleotides from E. col 157:H7:Elementary Sensitivity Tests" Journal of Sensors, vol. 9, 2009, pp 4890-4900.

[7] Samoc A., Miniewicz A., Samoc M., Grote J. G., "Refractive-Index Anisotropy and Optical Dispersion in Films of Deoxyribonucleic Acid", Journal of Apply Pol. Sci., vol. 105, 2007, pp 236245.

[8] Shew B.Y., Kuo C.H., Huang Y.C., Tsai Y. H. , “UVLIGA interferometer biosensor based on the SU8 optical waveguide", Journal of Sensors and Actuators A: Physical, Vol. 120, Issue 2, 2005, pp. 383-389.

[9] Grego S., McDaniel J. R., and Stoner B. R., "Wavelength interrogation of Grating based optical biosensors in the input coupler configuration", Journal of Sensors and Actuators B: Chemical, vol. 131, Issue 2, 2008, pp 347-355.

[10] Government of Western Australia, Department of Agriculture and Food, http://www.agric.wa. gov.au/PC 93298.html Viewed on the 22 July 2009 